\title{
Etiology of diarrheal infections in children of Porto Velho (Rondonia, Western Amazon region, Brazil)
}

\section{P.P. Orlandi ${ }^{1}$, G.F. Magalhães ${ }^{1}$, N.B. Matos ${ }^{1}$, T. Silva ${ }^{1}$, M. Penatti ${ }^{2}$, P.A. Nogueira ${ }^{1}$ and L.H. Pereira da Silva ${ }^{1}$}

\author{
${ }^{1}$ Centro de Pesquisa em Medicina Tropical, Porto Velho, RO, Brasil \\ ${ }^{2}$ Hospital Infantil Cosme e Damião, Porto Velho, RO, Brasil
}

Correspondence

P.P. Orlandi

Microbiologia - CEPEM

BR $364, \mathrm{~km} 4.5$

Caixa Postal 87

78900-970 Porto Velho, RO

Brasil

Fax: +55-69-225-9345

E-mail: pnogueir@cepem.com.br

Research supported by CNPq.

Received September 9, 2004 Accepted December 2, 2005

\section{Abstract}

In the present study, 470 children less than 72 months of age and presenting acute diarrhea were examined to identify associated enteropathogenic agents. Viruses were the pathogens most frequently found in stools of infants with diarrhea, including 111 cases of rotavirus (23.6\% of the total diarrhea cases) and 30 cases of adenovirus (6.3\%). The second group was diarrheogenic Escherichia coli (86 cases, 18.2\%), followed by Salmonella sp (44 cases, 9.3\%) and Shigella sp (24 cases, $5.1 \%$ ). Using the PCR technique to differentiate the pathogenic categories of $E$. coli, it was possible to identify 29 cases (6.1\%) of enteropathogenic E. coli (EPEC). Of these, 10 (2.1\%) were typical EPEC and $19(4.0 \%)$ atypical EPEC. In addition, there were 26 cases (5.5\%) of enteroaggregative E. coli, 21 cases (4.4\%) of enterotoxigenic $E$. coli, 7 cases (1.4\%) of enteroinvasive E. coli (EIEC), and 3 cases $(0.6 \%)$ of enterohemorrhagic E. coli. When comparing the frequencies of diarrheogenic E. coli, EPEC was the only category for which significant differences were found between diarrhea and control groups. A low frequency of EIEC was found, thus EIEC cannot be considered to be a potential etiology agent of diarrhea. Simultaneous infections with two pathogens were found in 39 diarrhea cases but not in controls, suggesting associations among potential enteropathogens in the etiology of diarrhea. The frequent association of diarrheogenic E. coli strains was significantly higher than the probability of their random association, suggesting the presence of facilitating factor(s).

\section{Introduction}

Persistent and recurrent acute diarrhea is one of the three major causes of morbidity and mortality in the world and accounts for an estimated annual five million deaths among infants under 5 years (1). Diarrhea continues to be endemic in some tropical and subtropical areas and is one of the leading
Key words

- Diarrheal disease

- Enteropathogens

- Escherichia coli

- Epidemiology

- Western Amazon causes of disability-adjusted life years $(2,3)$.

WHO reports show that in Latin America diarrhea accounts for more than $20 \%$ of childhood mortality (4). In poor urban areas of the Brazilian Northeast, longitudinal studies found averages of 4 to 6 diarrhea episodes per child/per year, corresponding to 20 to 40 days of diarrhea per year among children aged 3 to 24 months $(2,5)$. A longitudinal 
study performed in the city of Belém, in the Eastern Amazon region, found 5.9 diarrhea episodes per child per year (6).

Several studies have been conducted in the South and Southeast regions of Brazil in order to identify etiological agents associated with diarrhea and to assess the clinical and epidemiological features of the disease (7-14). These studies emphasized the importance of different diarrheogenic Escherichia coli strains and their respective genetic virulence determinants.

Few studies on the etiology of diarrhea were performed in urban and peri-urban areas of the Northeast, Central and Northern regions of Brazil. In these regions, the generalized poor quality or absence of sanitation and of a clean water supply for the population introduce additional risk factors for the morbi-mortality of infant diarrhea. In previous studies conducted in Fortaleza (Northeast Brazil) by Guerrant et al. (5) rotavirus appeared to be responsible for $21 \%$ of children's diarrhea cases, followed by Shigella and Campylobacter. Diarrheogenic E. coli was found only in $4.6 \%$ of cases. However, more recent studies by the same group have emphasized the importance of different pathogenic $E$. coli strains in persistent diarrhea (2). Other recent studies in

\begin{tabular}{|c|c|c|c|c|}
\hline \multirow[t]{2}{*}{$\begin{array}{l}\text { Age } \\
\text { (months) }\end{array}$} & \multicolumn{2}{|c|}{$\begin{array}{l}\text { Diarrhea } \\
\text { group }\end{array}$} & \multicolumn{2}{|c|}{$\begin{array}{l}\text { Control } \\
\text { group }\end{array}$} \\
\hline & $N$ & $\%$ & $\mathrm{~N}$ & $\%$ \\
\hline $0-12$ & 251 & 53.3 & 181 & 44.5 \\
\hline $13-24$ & 157 & 33.4 & 152 & 37.3 \\
\hline $25-36$ & 24 & 5.1 & 40 & 9.8 \\
\hline $37-48$ & 19 & 4.2 & 15 & 3.7 \\
\hline $49-60$ & 7 & 1.4 & 12 & 3.0 \\
\hline $61-72$ & 12 & 2.6 & 7 & 1.7 \\
\hline Total & 470 & 100 & 407 & 100 \\
\hline
\end{tabular}

the Northeast have confirmed the dominant frequency of rotavirus ( $21.5 \%$ of cases) and Shigella $(16.5 \%)$ with a lower frequency of enteropathogenic E. coli (EPEC). An interesting observation in this study (2) was the finding of diffusely adherent $E$. coli, a new category of pathogenic E. coli, detected as an important agent of diarrhea in children over 12 months of age (15). Studies in the Amazon region are even more infrequent. In the city of Belém, Linhares and co-workers $(6,16)$ identified rotavirus as the major etiological agent of infant diarrhea and studied the subgroups of viruses found in nosocomial cases $(6,16)$.

In the Western Amazon region, the only available information concerns a previous study by our group with preliminary data on the enteropathogens associated with diarrheal disease in infants from Porto Velho, RO, in the Western Amazon region (17). Among 130 cases of diarrhea, rotavirus appeared as the major etiological agent, followed by Shigella and Salmonella.

The present study was carried out in a children's Hospital of Porto Velho which attends children from the poor periphery of the city. We studied 470 patients with diarrhea and 407 age-matched controls less than 5 years of age. An estimation of associated pathogens showed that rotavirus was the major etiological agent associated with diarrhea cases. However, in contrast to our previous preliminary results, pathogenic $E$. coli strains appear to be the second most frequent group associated with diarrhea. Genetic determinants of virulence were identified among E. coli pathogenic strains from diarrhea cases and age-matched controls.

\section{Material and Methods}

\section{Study population}

Source of specimens. A total of 470 children under 72 months of age with acute diarrhea lasting at least $48 \mathrm{~h}$ and 407 age- 
matched controls (Table 1) were examined between March 2000 and March 2002 in the Emergency Section of Hospital Infantil Cosme Damião, Porto Velho, RO, Brazil. Relevant clinical information was collected by means of a standard questionnaire, including age, sex, clinical status (fever, vomiting, and dehydration status), type and duration of diarrhea, type of water consumed, breast-feeding, and a history of antibiotic therapy prior to the visit. Diarrhea was defined as the passage of three or more loose stools within the previous $24 \mathrm{~h}$ that conformed to the shape of the container. Dehydration was classified as absent, mild, moderate, or severe according to standard criteria (18).

Control children without diarrhea matched for age, sex, and socioeconomic status were recruited from the same Hospital. These children attended the hospital for non-diarrhea illnesses during the same period of time as the children with diarrhea and had not had diarrhea or other gastrointestinal symptoms or antibiotic therapy during the two preceding weeks.

Data concerning breast-feeding practice by each child's mother as well as the sanitation and condition of the water supply in their respective residences were collected at admission to the study. Information about the use of treated or untreated water in the preparation of food was also obtained.

\section{Search for pathogens in the stools}

Fecal samples were collected after natural evacuation or through stimulation with a glycerin suppository. Stools were divided into two fractions: one was used for parasitologic examination for helminth eggs and protozoan cysts by the method of Hoffman et al. (19). The same fraction was tested for the presence of rotavirus using the Slidex kit of Richmond (Rich Diagnostics, New Brunswick, NJ, USA) and enzyme-linked immunosorbent assays using kits from Biomanguinhos (EIARA-Biomanguinhos, Rio de Ja- neiro, RJ, Brazil). The second aliquot was processed by routine microbiological and biochemical tests from Biomerieux (Paris, France; API 20E) to identify E. coli, Salmonella spp, Shigella spp and Yersinia enterocolitica. Three to 5 lactose-fermenting colonies and up to 3 lactose-negative colonies from each child were selected from MacConkey (Difco, Le Pont de Claix, France) plates to be tested by standard and PCR procedures. Shigella and Salmonella strains were selected from SS agar, XLD agar, and VB agar (Difco). Y. enterocolitica strains were identified by means of a polyvalent serum (Y. enterocolitica polyvalent) and four monovalent sera: 03, 05, 08, and 09 (Probac, São Paulo, SP, Brazil).

\section{DNA of Escherichia coli strains used as control in PCR}

The positive control E. coli strains used for PCR included: EDL933 (for Shiga-like toxins I and II, H10407 (for heat-labile toxins [LT] and stable-labile [ST] enterotoxins); EDL1284 (for invasion); E2348/69 (for EPEC adherence factor, and attachment-effacement factor); 17-2 (for aggregative adherence), and C1845 (for diffuse adherence).

The non-pathogenic E. coli strain HB101 was used as negative control and to monitor PCR contamination.

\section{DNA extraction}

The bacteria were grown in $\mathrm{LB}$ at $37^{\circ} \mathrm{C}$ with shaking. DNA was extracted from centrifuged $(12,000 \mathrm{~g}, 10 \mathrm{~min})$ bacterial pellets or bacterial colonies after suspension in $0.9 \%$ $\mathrm{NaCl}$ solution. The suspension was incubated for $30 \mathrm{~min}$ at $37^{\circ} \mathrm{C}$. Bacterial cells were lysed in a solution containing $200 \mu \mathrm{L} 2$ M Tris, 0.5 M EDTA, and 10,000 U/mL lysozyme in water. The sample was boiled in a water bath for 10 min to completely lyse the bacteria. PCR was performed directly using the bacterial extract in 0.5-mL Eppen- 
dorf tubes on a BioRad Thermal cycler (London, UK) in a reaction volume of $50 \mu \mathrm{L}$.

\section{PCR procedures}

PCR amplifications were performed as follows: $5.0 \mu \mathrm{L}$ of bacterial extract was added to the reaction mixture with a final volume of $50 \mu \mathrm{L}$ containing $0.1 \mathrm{mM}$ each dATP, dCTP, dGTP and dTTP, PCR buffer $(10 \mathrm{mM}$ Tris-HCL, $\mathrm{pH} 8.3,50 \mathrm{mM} \mathrm{KCl}, 2 \mathrm{mM}$ $\mathrm{MgCl}_{2}$ ), $10 \mathrm{pMol}$ of each PCR primer, and 1 U Taq DNA polymerase. Amplification was performed in a BioRad thermal cycler, as follows: denaturation for $30 \mathrm{~s}$ at $92^{\circ} \mathrm{C}$, annealing for $1 \mathrm{~min}$ at $57^{\circ} \mathrm{C}$, and extension for $1 \mathrm{~min}$ at $72^{\circ} \mathrm{C}$ ( 30 cycles). The amplification process was followed by a 5-min extension at $72^{\circ} \mathrm{C}$, and the tubes were rapidly cooled to $4^{\circ} \mathrm{C}$. The amplified DNA products were resolved by agarose gel electrophoresis $(2 \%)$ and visualized by UV trans-illumination after ethidium bromide staining.

\section{Analysis of virulence factors of Escherichia coli by PCR}

To determine the presence of diarrheogenic E. coli among the selected subcultures, PCR tests were carried out for genes encoding thermolabile toxins (LT-I and LTII) and thermostable toxins (STI) produced by enterotoxigenic E. coli (ETEC) and verotoxin types 1,2 , and $2 \mathrm{e}$ produced by enterohemorrhagic E. coli (EHEC). Oligonucleotide primers used to detect specific virulence determinants are presented in Table 2. Other factors such as enteroaggregative

Table 2. Sequences of PCR primers and expected product sizes.

\begin{tabular}{|c|c|c|c|c|}
\hline Pathogens & Gene & Primer & $\begin{array}{l}\text { Expected product } \\
\text { size (nucleotides) }\end{array}$ & Reference \\
\hline EHEC & VT1 & $\begin{array}{l}\text { fp: 5'-ACGTTACAGCGTGTTGCRGGGATC-3' } \\
\text { bp: 5'-TTGCCACAGACTGCGTCAGTRAGG-3' }\end{array}$ & 121 & 20 \\
\hline EHEC & VT2 & $\begin{array}{l}\text { fp: 5'-TGTGGCTGGGTTCGTTAATACGGC-3' } \\
\text { bp: 5'-TCCGTTGTCATGGAAACCGTTGTC-3' }\end{array}$ & 102 & 20 \\
\hline EHEC & VT2e & $\begin{array}{l}\text { fp: 5'-CCAGAATGTCAGATAACTGGCGAC-3' } \\
\text { bp: 5'-GCTGAGCACTTTGTAACAATGGCTG-3' }\end{array}$ & 322 & 20 \\
\hline EHEC & HLY & $\begin{array}{l}\text { fp: 5'-GGTGCAGCAGAAAAAGTTGTA-3' } \\
\text { bp: 5'-TCTCGCCTGATAGTGTTTGG-3' }\end{array}$ & 1551 & 15 \\
\hline EPEC & eae & $\begin{array}{l}\text { fp: 5'-TGAGCGGCTGGCATGAGTCATAC-3' } \\
\text { bp: 5'-TCGATCCCCATCGTCACCAGAGG-3' }\end{array}$ & 241 & 20 \\
\hline EPEC & $b f p$ & $\begin{array}{l}\text { fp: 5'-AATGGTGCTTGCGCTTGCTGC-3' } \\
\text { bp: 5'-GCCGCTTTATCCAACCTGGTA-3' }\end{array}$ & 324 & 21 \\
\hline EPEC & EAF & $\begin{array}{l}\text { fp: 5'-CAGGGTAAAAGAAAGATGATAA-3' } \\
\text { bp: 5'-TATGGGGACCATGTATTATCA-3' }\end{array}$ & 397 & 22 \\
\hline ETEC & LT-I & $\begin{array}{l}\text { fp: 5'-TGGATTCATCATGCACCACAAGG-3' } \\
\text { bp: 5'-CCATTTCTCTTTTGCCTGCCATC-3' }\end{array}$ & 360 & 20 \\
\hline ETEC & STI & $\begin{array}{l}\text { fp: 5'-TTTCCCCTCTTTTAGTCAGTCAACTG-3' } \\
\text { bp: 5'-GGCAGGATTACAACAAAGTTCACAG-3' }\end{array}$ & 160 & 20 \\
\hline EIEC & Einv & $\begin{array}{l}\text { fp: 5'-TGGAAAAACTCAGTGCCTCTGCGG-3' } \\
\text { bp: 5'-TTCTGATGCCTGATGGACCAGGAG-3' }\end{array}$ & 140 & 20 \\
\hline EAEC & Eagg & $\begin{array}{l}\text { fp: 5'-AGACTCTGGCGAAAGACTGTATC-3' } \\
\text { bp: 5'-ATGGCTGTCTGTAATAGATGAGAAC-3' }\end{array}$ & 194 & 20 \\
\hline
\end{tabular}

$\mathrm{EHEC}=$ enterohemorrhagic Escherichia coli $\mathrm{EPEC}=$ enteropathogenic $E$. coli; $\mathrm{ETEC}=$ enterotoxigenic $E$. coli; $\mathrm{EIEC} \mathrm{=} \mathrm{enteroinvasive} \mathrm{E.} \mathrm{coli;} \mathrm{EAEC}=$ enteroaggregative $E$. coli; $\mathrm{VT} 1, \mathrm{VT} 2, \mathrm{VT} 2 \mathrm{e}=$ verotoxin types 1,2 , and 2e, respectively; $\mathrm{HLY}=$ hemolysin: $\mathrm{EAF}=\mathrm{EPEC}$ adherence factor; $\mathrm{LT}-\mathrm{I}=$ heat labile toxin $\mathrm{I} ; \mathrm{STI}=$ stablelabile enterotoxin; Einv and Eagg = enteroinvasive and enteroaggregative mechanisms, respectively. $\mathrm{fp}=$ forward primer; $b p=$ backward primer. "R" in primers VT1 fp and VT1 bp can be A or G. 
mechanisms, and enteroinvasive mechanisms were also analyzed. The following factors were analyzed in order to characterize the EPEC strains: a fragment of the eae gene, the $b f p A$ gene, the EPEC adherence factor plasmid, and the locus for enterocyte effacement insertion site.

\section{Statistical analysis}

The prevalence of diarrheogenic E. coli in patients and controls was compared by the two-tailed $\chi^{2}$ test and Fisher's exact test with Yates' correction. When analyzing the association of two or three pathogens in the same diarrheal patient, the same test was used to evaluate the probability of association by random chance as a function of their respective individual frequency in the population.

\section{Results}

\section{Pathogens associated with diarrhea}

Table 3 describes the number of pathogenic and non-pathogenic agents detected in the stools of both groups. Enterovirus was the major cause of disease in the diarrhea group (30\%), while rotavirus and adenovirus were found in $111(23.6 \%)$ and $30(6.3 \%)$ stools, respectively, among the 470 patients. However, enterovirus was also found in $11.7 \%$ of the stools from the control group (Table 3).

Diarrheogenic E. coli was found in 86 $(18.2 \%)$ children with diarrhea, representing the second group in order of frequency. For this reason, the characterization of diarrheogenic E. coli was performed by PCR. EPEC was the strain most frequently associated with diarrhea $(6.1 \%$ of cases, with $2.1 \%$ being typical EPEC and $4.0 \%$ atypical EPEC), followed by enteroaggregative $E$. coli (EAEC) $(5.5 \%)$ and ETEC (4.4\%). Enteroinvasive E. coli (EIEC) and EHEC strains were found at lower frequencies, with only 7 cases $(1.4 \%)$ and 3 cases $(0.6 \%)$, respective- ly. However, it is important to emphasize that these two minor variants were found only in patients with diarrhea and not in the controls.

Among other enteropathogenic bacteria, Salmonella sp with 44 cases $(9.3 \%)$ and Shigella species with 24 cases (5.1\%) were in third and fourth positions, respectively. All of these pathogenic bacteria were isolated from the control group, but at lower frequencies (Table 3 ). $Y$. enterocolitica was isolated in 4 cases $(0.8 \%)$.

\section{Pathogens found in matched controls}

The major pathogens were found in stools of age-matched children from the control group (Table 3), but their frequency was significantly lower compared to the infected group. Comparing the number of stools from which enterovirus was isolated, 141 from the diarrhea group $(\mathrm{N}=470)$ and 48 from control group $(\mathrm{N}=407)$, a $\chi^{2}$ Mantel Haenszel of 42.72 was observed $(\mathrm{P}<0.0000001)$. One hundred and one rotaviruses found in the diarrhea group and 41 in the control give a $\chi^{2}$ Mantel Haenszel of $27.89(\mathrm{P}=0.0000001)$. For adenovirus the $\chi^{2}$ Mantel Haenszel was 11.72 , with $\mathrm{P}=0.0006$ (30 in diarrhea group and 7 in the control group).

The frequency of all diarrheogenic $E$. coli strains was significantly higher in the diarrhea group than in the control group, with 86 and 39 isolates, respectively $\left(\chi^{2}\right.$ Mantel Haenszel $=$ 13.54; $\mathrm{P}=0.0001)$. The frequencies of 29 EPEC in the diarrhea group and 8 in the control group were significantly different $\left(\chi^{2}\right.$ Mantel Haenszel $\left.=9.53 ; \mathrm{P}=0.002\right)$. However, the difference was no longer significant when we analyzed typical EPEC individually. Regarding EIEC, the $\chi^{2}$ Mantel Haenszel was 6.01 (P $=0.01)$. The frequency of EHEC was too low for the use of statistical tests and the frequencies of EAEC and ETEC were not significantly different between the diarrhea and control groups.

Significant differences were also ob- 
served when comparing the frequencies of Salmonella $\operatorname{sp}\left(\chi^{2}\right.$ Mantel Haenszel $=16.39 ; \mathrm{P}=$ $0.00005)$ and Shigella sp $\chi^{2}$ Mantel Haenszel $=$ $18.59 ; \mathrm{P}=0.00001$ ) between groups.

Other bacteria, enteropathogenic proto- zoa and worms were found at similar levels in the stools of both groups. The data obtained for enteropathogenic protozoa represent an underestimate since no specific examination was performed for Cryptospori-

Table 3. Pathogenic and non-pathogenic agents isolated from stools of children with diarrhea and agematched controls.

\begin{tabular}{|c|c|c|c|c|}
\hline \multirow[t]{2}{*}{ Agent } & \multicolumn{2}{|c|}{ No. of stools (\% positive) } & \multirow[t]{2}{*}{$\chi^{2}$} & \multirow[t]{2}{*}{$\mathrm{P}$} \\
\hline & $\begin{array}{l}\text { Diarrhea group } \\
\qquad(\mathrm{N}=470)\end{array}$ & $\begin{array}{l}\text { Control group } \\
\qquad(\mathrm{N}=407)\end{array}$ & & \\
\hline \multicolumn{5}{|l|}{ Enterovirus } \\
\hline Rotavirus & $111(23.62)$ & $41(10.07)$ & 27.89 & $<0.00001$ \\
\hline Adenovirus & $30(6.38)$ & $7(1.71)$ & 11.72 & $=0.006$ \\
\hline Total & $141(30.01)$ & $48(11.78)$ & 42.72 & $<0.00001$ \\
\hline \multicolumn{5}{|c|}{ Diarrheogenic Escherichia coli } \\
\hline EPEC & $29(6.17)$ & $8(1.96)$ & 9.53 & $=0.002$ \\
\hline Typical EPEC & $10(2.13)$ & $6(1.47)$ & 0.52 & NS \\
\hline Atypical EPEC & $19(4.04)$ & $2(0.49)$ & 11.76 & $=0.006$ \\
\hline ETEC & $21(4.46)$ & $14(3.43)$ & 0.6 & NS \\
\hline EIEC & $7(1.48)$ & $0(0)$ & 6.1 & $=0.01$ \\
\hline EAEC & $26(5.53)$ & $17(4.17)$ & 0.86 & NS \\
\hline EHEC & $3(0.63)$ & $0(0)$ & ND & - \\
\hline Total & $86(18.27)$ & $39(9.58)$ & 13.54 & $=0.0001$ \\
\hline \multicolumn{5}{|c|}{ Other enteropathogenic bacteria } \\
\hline Salmonella & $44(9.36)$ & $9(2.21)$ & 16.39 & $=0.00005$ \\
\hline Shigella & $24(5.10)$ & $1(0.24)$ & 18.59 & $=0.00001$ \\
\hline Yersinia enterocolitica & $4(0.85)$ & $0(0)$ & ND & - \\
\hline Total & $72(15.31)$ & $10(2.45)$ & ND & - \\
\hline \multicolumn{5}{|l|}{ Other bacteria } \\
\hline Hafnia alvei & $21(4.46)$ & $18(4.42)$ & 0.0 & NS \\
\hline Klebsiella sp & $21(4.46)$ & $14(3.43)$ & 0.6 & NS \\
\hline Morganella morgani & $2(0.42)$ & $0(0)$ & ND & - \\
\hline Serratia marcercens & $98(20.85)$ & $99(24.32)$ & 1.5 & NS \\
\hline Enterobacter cloacae & $27(5.74)$ & $22(5.40)$ & 0.05 & NS \\
\hline Proteus mirabilis & $5(1.06)$ & $2(0.49)$ & ND & - \\
\hline Total & $174(37.00)$ & $155(38.06)$ & 0.1 & NS \\
\hline \multicolumn{5}{|l|}{ Intestinal parasites } \\
\hline Ascaris lumbricoides & $21(4.46)$ & $22(5.40)$ & 0.41 & NS \\
\hline Entamoeba coli & $3(0.63)$ & $0(0)$ & ND & - \\
\hline Entamoeba histolytica & $10(2.12)$ & $1(0.24)$ & 6.23 & $=0.01$ \\
\hline Giardia lamblia & $6(1.27)$ & $4(0.98)$ & ND & - \\
\hline Hymenolepis nana & $3(0.63)$ & $1(0.24)$ & ND & - \\
\hline Strongiloides stercoralis & $3(0.63)$ & $0(0)$ & ND & - \\
\hline Trichuris trichiura & $5(1.06)$ & $1(0.24)$ & ND & - \\
\hline Total & $51(10.85)$ & $29(7.12)$ & 3.65 & 0.056 \\
\hline
\end{tabular}

Data are reported as the number of stools from children in the diarrhea and control groups from which each pathogen was isolated and the percentage of each pathogen isolated from the stools of the children in each group. A total of 281 pathogenic or non-pathogenic agents were isolated from the control group. No enteropathogen was isolated from the stools of 126 control children. For abbreviations of Escherichia coli strains, see legend to Table 2. The two-tailed $\chi^{2}$ Mantel Haenszel test and Fisher's exact test with Yates corrections were used for statistical analysis. ND = not determined; NS = not significant. 
dium. In addition, the Hoffman technique adopted for parasitological stool examination is valid only for the detection of cysts and not of the vegetative protozoan forms that are present in acute diarrhea stools. Nevertheless, other bacteria and intestinal parasites were found in the diarrhea group, sometimes simultaneously, increasing the number of isolates in the diarrhea group. These minor enteropathogens were found in stools of the control group, with frequencies similar to the diarrhea group. The exception was Entamoeba histolytica, whose frequencies in both groups were statiscally different $\left(\chi^{2}\right.$ Mantel Haenszel $\left.=6.23 ; \mathrm{P}=0.01\right)$.

In summary, the frequencies of all major enteropathogens such as enterovirus, diarrheogenic E. coli and other enteropathogenic bacteria were higher in the diarrhea group (Table 3).

Analysis by the $\chi^{2}$ test for linear trend in proportions (Epi-6 package) was performed to determine whether the presence of some diarrheogenic E. coli strains was dependent on age in both groups. Although only 9 diarrheogenic E. coli strains were isolated from children older than 24 months (Table 4), no significant difference was found between the diarrhea and control groups by linear trend in proportions, nor were any differences detected for EPEC, EAEC or ETEC (Table 4).

It was possible to characterize the etiology of diarrhea in 299 stool samples from the 470 children in the diarrhea group by the presence of potential pathogenic agents (141 cases of enterovirus, 86 of diarrheogenic $E$. coli, and 72 of other enteropathogenic bacteria, Table 3), whereas the etiology of diarrhea could not be identified in the other 171 children.

It is important to note that simultaneous infection with more than one potential enteropathogen was observed in 39 stool samples from the diarrhea group, whereas no case of simultaneous infection was observed in the control group. Rotavirus and enteropathogenic bacteria were isolated in 18 cases. Among the diarrheogenic E. coli, EPEC was the major category with simultaneous infection, with 26 cases of 29 detected in the diarrhea group.

Simultaneous infection found in stools with potential enteropathogens could be important to the etiology of diarrhea. Table 5 shows that i) among 111 rotavirus-positive stools from the diarrhea group, a combination of different enteropathogens was detected in 18 samples, Shigella spp in 3 cases, Salmonella in 7 cases, and diarrheogenic $E$. coli in 8 cases (EIEC in 2 cases, EAEC in 1 case and EPEC in 5 cases). Although rotavirus was isolated from 41 stools of the control group, no other enteropathogen was detected in simultaneous infection $\left(\chi^{2}\right.$ Yates 6.07; Fisher-2t $=0.0035)$. ii) The more surprising finding of simultaneous infection was observed with different diarrheogenic $E$. coli. Twenty-six potential enteropathogens were detected in 29 EPEC-positive stools from

\begin{tabular}{|c|c|c|c|c|c|c|}
\hline E. colia & $\begin{array}{c}\text { Age } \\
\text { (months) }\end{array}$ & $\begin{array}{c}\text { Diarrhea } \\
\mathrm{N}(\%)\end{array}$ & $\begin{array}{l}\text { Control } \\
\mathrm{N}(\%)\end{array}$ & $\begin{array}{c}\text { OR } \\
(95 \% \mathrm{Cl})\end{array}$ & $\chi^{2}$ & $P$ \\
\hline \multirow[t]{3}{*}{ EPEC } & $0-12$ & $15(3.2)$ & $6(1.5)$ & Reference & 1.67 & 0.196 \\
\hline & $13-24$ & $11(2.3)$ & $2(0.5)$ & 2.20 & & NS \\
\hline & $25-72$ & $3(0.6)$ & $0(0.0)$ & $\mathrm{NC}$ & & \\
\hline \multirow[t]{3}{*}{ EAEC } & $0-12$ & $13(2.7)$ & $9(2.2)$ & Reference & 0.173 & 0.677 \\
\hline & $13-24$ & $10(2.1)$ & $7(1.7)$ & 0.99 & & NS \\
\hline & $25-72$ & $3(0.6)$ & $1(0.2)$ & 2.08 & & \\
\hline \multirow[t]{3}{*}{ ETEC } & $0-12$ & $8(1.7)$ & $6(1.5)$ & Reference & 0.108 & 0.742 \\
\hline & $13-24$ & $11(2.3)$ & $7(1.7)$ & 1.18 & & NS \\
\hline & $25-72$ & $2(0.4)$ & $1(0.2)$ & 1.50 & & \\
\hline All & $0-12$ & $39(8.3)$ & $21(5.2)$ & Reference & 1.22 & 0.264 \\
\hline diarrheogenic & $13-24$ & $38(8.1)$ & $16(3.9)$ & 1.28 & & NS \\
\hline E. colib & $25-72$ & $9(1.9)$ & $2(0.5)$ & 2.42 & & \\
\hline
\end{tabular}

Data are reported as the number (\%) of children in both groups from whom these diarrheogenic $E$. coli were isolated. ${ }^{a}$ Only these categories of diarrheogenic $E$. coli could be investigated because of the low frequencies of other categories. ${ }^{b} A l l$ diarrheogenic E. coli = EPEC, ETEC, DAEC, EIEC, EHEC. For abbreviations of E. coli strains, see legend to Table 2. Odds ratios (OR) and 95\% confidence intervals (95\% $\mathrm{Cl}$ ) were used to determine associations. Analysis by the $\chi^{2}$ test for linear trend in proportions using the STATCALC calculator of the Epi-6 package was utilized to determine whether the presence of some diarrheogenic $E$. coli were dependent on age in both groups. $\mathrm{NC}=$ not calculated; NS = not significant. 
the diarrhea group (rotavirus in 5 cases, ETEC $^{\mathrm{LT}+/ \mathrm{ST}+}$ in 8 cases, EIEC in 4 cases, and EAEC in 9 cases). Among 8 EPEC-positive stools from the control group, no other enteropathogen was detected. This difference was statistically significant $\left(\chi^{2}\right.$ Yates 20.02; Fisher- $2 t=0.0000043)$. When we analyzed the frequencies of EAEC, ETEC or EIEC individually in relation to the EPECpositive stools of both groups, the differences

Table 5. Description and chi-square analysis of associated pathogens in the diarrhea group.

\begin{tabular}{|c|c|c|c|}
\hline \multirow[t]{2}{*}{$\begin{array}{l}\text { Simultaneous infection } \\
\text { or association between } \\
\text { potential enteropathogens }\end{array}$} & \multicolumn{2}{|c|}{$\begin{array}{c}\text { No. of children in whom } \\
\text { associations were found } \\
\text { (No. of specific pathogens found) }\end{array}$} & \multirow[t]{2}{*}{$\begin{array}{l}\chi^{2} \text { Yates corrected } \\
\text { Fisher } 2 \mathrm{t}\end{array}$} \\
\hline & Diarrhea group & Control group & \\
\hline $\begin{array}{l}\text { aRotavirus associated with } \\
\text { different pathogens }\end{array}$ & $18(111)$ & $0(41)$ & $\begin{array}{l}\chi^{2}=6.07 \\
P=0.0035\end{array}$ \\
\hline $\begin{array}{l}\text { bEPEC associated with other } \\
\text { pathogens }\end{array}$ & $26(29)$ & $0(8)$ & $\begin{array}{c}\chi^{2}=20.02 \\
P=0.0000043\end{array}$ \\
\hline${ }^{C} E P E C$ associated with EAEC & $9(29)$ & $0(8)$ & Not significant \\
\hline $\begin{array}{l}{ }^{\text {d}} \text { EPEC associated with } \\
\text { ETEC }\end{array}$ & $8(29)$ & $0(8)$ & Not significant \\
\hline${ }^{e}$ EPEC associated with EIEC & $4(29)$ & $0(8)$ & Not significant \\
\hline${ }^{\mathrm{f}} \mathrm{EAEC}$ associated with EPEC & $9(26)$ & $0(17)$ & $\begin{array}{c}\chi^{2}=5.50 \\
P=0.0067\end{array}$ \\
\hline $\begin{array}{l}\text { gETEC } C^{\mathrm{LT}+/ \mathrm{ST}+} \text { associated } \\
\text { with EPEC }\end{array}$ & $8(21)$ & $0(14)$ & $\begin{array}{l}\chi^{2}=4.92 \\
P=0.01\end{array}$ \\
\hline${ }^{h}$ EIEC associated with EPEC & $4(7)$ & $0(0)$ & Not done \\
\hline
\end{tabular}

aln 18 of 111 rotavirus-positive samples from the diarrhea group, different pathogens were found in association with rotavirus: Shigella spp in 3 cases, Salmonella spp in 7 cases, diarrheogenic Escherichia coli in 8 cases (EIEC: 2 cases; EAEC: 1 case, EPEC: 5 cases). In 41 stool samples from the control group in which rotavirus was identified, no association was found. bIn 26 of 29 EPEC-positive samples from the diarrhea group, associations with rotavirus or different diarrheogenic E. coli strains were found: rotavirus in 5 cases, ETEC (LT+/ST+) in 8 cases, EIEC in 4 cases, and EAEC in 9 cases. In 8 stool samples from the control group from which EPEC was isolated, no association was found. CIn 29 EPEC-positive samples from the diarrhea group, we analyzed specific association between EPEC and EAEC. dIn 29 EPECpositive samples from the diarrhea group, we analyzed specific association between EPEC and ETEC. eIn 29 EPEC-positive samples from the diarrhea group, we analyzed specific association between EPEC and EIEC. II 9 of 26 EAEC-positive samples from the diarrhea group, association with EPEC was detected. In 17 stool samples from the control group, from which EAEC was isolated, no association was found. 9In 8 of $21 \mathrm{ETECLT+/ST+-positive} \mathrm{samples} \mathrm{from} \mathrm{the} \mathrm{diarrhea} \mathrm{group,} \mathrm{EPEC} \mathrm{was} \mathrm{found} \mathrm{in} \mathrm{asso-}$ ciation with ETECLT+/ST+. In 14 stool samples from the control group, from which ETEC LT+/ST+ was isolated, no association was found. hIn 4 of 7 EIEC-positive samples from the diarrhea group, EPEC was found in association with EIEC. Since no EIEC was found in the stools from the control group, the analysis could not be done. For abbreviations of $E$. coli strains, see legend to Table 2. were not statistically significant (Table 5). However, the frequencies of EPEC in relation to EAEC-positive stools or ETEC ${ }^{\mathrm{LT}+/ \mathrm{ST}+}$-positive stools from the diarrhea and control groups were significantly different $\left(\chi^{2}\right.$ Yates corrected $=$ 5.50 and $\mathrm{P}=0.0067 ; \chi^{2}$ Yates corrected $=4.92$ and Fisher $2 \mathrm{t}=0.01$, respectively). Thus, we identified simultaneous infection only in the diarrhea group, suggesting associations of these potential enteropathogens in the etiology of diarrhea.

Differences in the frequency of ETEC strains and the presence of genetic markers corresponding to the described ETEC toxins were investigated in strains isolated from patients and controls (Table 6). No significant differences in the frequency of the individual markers LT and ST and toxins were observed between groups.

\section{Breast-feeding, consumption of treated water and diarrhea}

Breast-feeding, appropriate sanitation and a clean water supply were shown to be important factors for the protection of children against diarrhea. Analysis of the data from the questionnaire revealed that more than $85 \%$ of the mothers of both groups regularly breast-fed their children until 2 years of age or more. Treated water (filtered or boiled) was also commonly used by the mothers of children with diarrhea (78.8\%) and of the controls $(69.5 \%)$. However, there was no evidence that these measures significantly reduced diarrheal infections. We accepted the replies of the mothers as truthful and did not check these conditions by visiting their homes.

\section{Discussion}

The results of the present study confirm and extend data of our previous study (17) concerning the major importance of enterovirus, particularly rotavirus, as the principal etiologic agent in $23.6 \%$ cases of infant diar- 
rhea. This is also in agreement with other studies conducted in São Paulo (13) and in the Eastern Amazon region (6,23).

Studies of the interaction and importance of different pathogenic $E$. coli strains associated with acute diarrhea in Brazil have not fully clarified this issue. Pioneering studies by Gomes and co-workers in São Paulo (9) indicated EPEC as the major etiologic agent of infant diarrhea, with indices even higher than those of rotavirus. In a longitudinal study conducted in Fortaleza (2), only ETEC strains were significantly associated with diarrhea. Rodrigues and co-workers (11) suggested that EAEC is the major diarrheogenic E. coli strain, either alone or in association with rotavirus. In our preliminary study, we had identified EPEC, ETEC and EIEC strains in association with diarrhea but the number of cases was too small for statistical analysis. In the present study, among diarrheogenic E. coli strains, EPEC appears to be the major strain associated with diarrhea. There was a statistically significant association of EIEC or EHEC strains with EPEC in cases of diarrhea, in spite of the low number of registered cases. In contrast, no clear association of EAEC and ETEC with diarrhea was demonstrable. The frequencies of these strains in the stools of diarrheal cases and controls were not significantly different.

A recent study by Sperandio et al. (24) indicated that classical DNA markers alone are insufficient to define virulence. The study showed the existence of other still unsuspected genetic determinants, either directly linked to a pathogenic effect, such as adhesins and toxins, or acting indirectly through expression of virulent genes and/or on the secretion of their products. Elias Jr. and coworkers (7) have shown that the expression of aggregative adherence fimbria II depends on genetic factors present in two regions of a large plasmid. Elias and co-workers (25) deleted the $b f p$ operon responsible for the synthesis of bundle-forming pili. However, the deleted strain was still able to adhere to HEp-2 cells, indicating an alternative mechanism of adhesion. In 1998, Sperandio et al. (24) had shown that the locus for enterocyte effacement pathogenic island in the chromosome of E. coli presented a polymorphic structure for the 3 loci involved in the secretion of the eae gene product. More recently, in EPEC strains with a conserved locus for enterocyte effacement, they observed no differences between diarrhea cases and controls in relation to the presence of the eae gene (25). They concluded that the presence of eae is not sufficient to define virulence and assigned more significance to the results of fluorescent actin staining in the E. colicell interaction model, which reflects the interaction of intimin (the eae product) with the cell actin. The mechanisms of these interactions are presently not understood.

We found some simultaneous infection with rotavirus and different enteropathogens such as Shigella, Salmonella, and diarrheogenic E. coli, but the more striking fact was that diarrhea caused by EPEC seemed to occur only in association with other enteropathogens. In stools from the diarrhea group in which EPEC was detected, the frequency of simultaneous infection with rotavirus or other diarrheogenic E. coli was prominent, while in the eight isolates from the control group EPEC was the only pathogen present

Table 6. Genetic markers found in enterotoxigenic Escherichia coli (ETEC) isolated from children with diarrhea and age-matched controls.

\begin{tabular}{lcc}
\hline Pathogen and virulence marker & \multicolumn{2}{c}{ Frequency of a genetic marker } \\
\cline { 2 - 3 } & Diarrhea group (N=470) & Control group (N = 407) \\
\hline Isolated marker & & \\
ETEC (all markers) & $21(4.5 \%)$ & $14(3.4 \%)$ \\
LT & $10(2.1 \%)$ & $6(1.5 \%)$ \\
ST & $11(2.3 \%)$ & $8(1.9 \%)$ \\
Associated markers & & \\
LT-ST & $3(0.6 \%)$ & $2(0.4 \%)$ \\
\hline
\end{tabular}

Data are reported as number and percent. LT $=$ heat-labile toxin; $\mathrm{ST}=$ stable-labile enterotoxin. 
(Table 5). When we analyzed individually simultaneous infection of EPEC with the various categories of diarrheogenic $E$. coli, the differences were not significant, but when we analyzed EAEC or ETEC individually with EPEC these differences were significant, suggesting that there is an effect of the cooperation between these categories of $E$. coli and EPEC. The mechanisms of this cooperation are obscure; however, Elias Jr. and co-workers (7) recently reported an atypical adhesion profile in cell adhesion assays between EPEC isolates in the presence of O125:H6 EAEC from a diarrhea case. It has been speculated that simultaneous growth of associated EPEC and EAEC may be facilitated by horizontal transfer of genetic markers.

The most important finding of the present study in relation to the observations of Elias Jr. and co-workers (7) was the clear association of double (mixed) infections with diarrhea. No association of putative pathogens was found in stools from children of the control group, while 39 of the 470 children in the diarrhea group presented the association of two different pathogens as the etiologic agents of diarrhea (Table 5).

Diarrhea reflects bacterial proliferation in the gut, with increasing cell numbers that may eventually facilitate genetic exchange. The cytolethal distending toxin described in O86:H34 E. coli was also detected in other enteric bacteria such as Shigella and Campylobacter (26).

Adenoviruses, other bacterial pathogens like $Y$. enterocolitica, and protozoa (E. histolytica and Giardia lamblia) were also found in diarrhea cases at lower frequencies. However, the participation of enteropathogenic protozoa could not be properly evaluated since no specific examination for Cryptosporidium was performed and the parasitological stool examination used did not detect vegetative forms of Entamoeba and Giardia.
In the present study, the data concerning breast-feeding practice by each child's mother, as well as sanitation and water supply conditions in their respective residences, were collected at admission to the study. Information was also obtained about the use of treated or untreated water in the preparation of complementary food. There was no evidence that these measures represented a significant risk of diarrhea infection nor did they prevent infection.

The age distribution of diarrhea cases drops sharply after 24 months of age, suggesting the development of resistance against all etiologic agents. Immunity to enteropathogens should be investigated. One might speculate that mothers are less stressed and attentive to illness when their children start to develop greater autonomy after 2 years age. While our child sample corresponds to symptomatic patients looking for medical care at the Hospital, the age distribution in our study was the same as observed in an active search for cases in longitudinal studies (2).

However, in the long-term cohort study performed by Lima and co-workers (2) in a similarly poor area of Fortaleza, an active search of diarrhea cases also revealed a peak of diarrheal illnesses, with 6.8 episodes per child-year among 13- to 14-month-old children, followed by a sharp drop in number of acute episodes and persistent diarrhea. It is not clear if the mechanisms involved in protection against diarrhea are simultaneously developed against all the etiologic agents responsible for diarrhea in children. Alternatively, resistance may be related to some age-dependent mechanism and not to acquired immunity. The data obtained in the present study did not permit us to distinguish between these hypotheses. A study of larger samples of asymptomatic carriers in the critical transition age would be valuable to address this issue. 


\section{References}

1. Georges MC, Wachsmuth IK, Meunier DM et al. (1984). Parasitic, bacterial and viral enteric pathogens associated with diarrhea in the Central African Republic. Journal of Clinical Microbiology, 19: 571575.

2. Lima AA, Moore SR, Barboza Jr MS et al. (2000). Persistent diarrhea signals a critical period of increased diarrhea burdens and nutritional shortfalls: a prospective cohort study among children in Northeasten Brazil. Journal of Infectious Diseases, 181: 43-51.

3. Murray JL \& Lopez AD (1997). The Global Burden of Disease: A Comprehensive Assessment of Mortality and Disability from Diseases Injuries, and Risk Factors in 1900 and Projected to 2020. Harvard University Press, Cambridge, MA, USA.

4. Bern C, Martines J, de Zoysa I et al. (1992). The magnitude of the global problem of diarrhoeal disease: a ten years update. Bulletin of the World Health Organization, 70: 705-714.

5. Guerrant RL, Kirchhoff LV, Shields DS et al. (1983). Prospective study of diarrheal illnesses in Northeastern Brazil: patterns of disease, nutritional impact, etiologies, and risk factors. Journal of Infectious Diseases, 148: 986-997.

6. Linhares AC (1997). Rotavirus infection in Brazil: epidemiology, immunity, and potential vaccination. Brazilian Journal of Infectious Diseases, 1: 284-293.

7. Elias Jr WP, Czeczulin JR, Henderson IR et al. (1999). Organization of biogenesis genes for aggregative adherence fimbria II defines a virulence gene cluster in enteroaggregative Escherichia coli. Journal of Bacteriology, 181: 1779-1785.

8. Gomes TAT, Vieira MA, Abe CM et al. (1998). Adherence patterns and adherence-related DNA sequences in Escherichia coli isolates from children with and without diarrhea in São Paulo city, Brazil. Journal of Clinical Microbiology, 36: 3609-3613.

9. Gomes TAT, Rassi V, MacDonald KL et al. (1991). Enteropathogens associated with acute diarrheal disease in urban infants in São Paulo, Brazil. Journal of Infectious Diseases, 164: 1-7.

10. Riley LW, Ceballos BS, Trabulsi LR et al. (1984). The significance of hospitals as reservoirs for endemic multiresistant Salmonella typhimurium causing infection in urban Brazilian children. Journal of Infectious Diseases, 150: 236-241.

11. Rodrigues J, Acosta VC, Candeias JM et al. (2002). Prevalence of diarrheogenic Escherichia coli and rotavirus among children from Botucatu, São Paulo State, Brazil. Brazilian Journal of Medical and Biological Research, 35: 1311-1318.

12. Rodrigues J, Scaletsky ICA, Campos LC et al. (1996). Clonal structure and virulence factors in strains of Escherichia coli of the classic serogroup 055. Infection and Immunity, 64: 2680-2686.

13. Trabulsi LR, Toledo MRF, Ceballos BSO et al. (1985). Epidemiology of diarrhoeal diseases in South America. In: Takeda $Y$ \& Miwatani $T$ (Editors), Infectious Diarrhoea in the Young. Vol. 12. Elsevier Science Publisher, Amsterdam, The Netherlands, 121-125.

14. Trabulsi LR, Toledo MRF, Murahovschi J et al. (1985). Epidemiol- ogy of infantile bacterial diarrheal disease in Brazil. Bacterial Diarrheal Diseases, 20: 25-36.

15. Scaletsky ICA, Fabbricotti SH, Carvalho RLB et al. (2002). Diffusely adherent Escherichia coli as a cause of acute diarrhea in young children in Northeast Brazil: a case-control study. Journal of Clinical Microbiology, 40: 645-648.

16. Mascarenhas JD, Gusmão RH, Barardi CR et al. (1999). Characterization of rotavirus $\mathrm{P}$ genotypes circulating among pediatric inpatients in northern Brazil. Revista do Instituto de Medicina Tropical de São Paulo, 41: 165-170.

17. Orlandi PP, Silva T, Magalhães GF et al. (2001). Enteropathogens associated with diarrheal disease in infants of poor urban areas of Porto Velho, Rondônia: a preliminary study. Memórias do Instituto Oswaldo Cruz, 96: 621-625.

18. Faruque AS, Mahalanabis D, Islam A et al. (1993). Common diarrhea pathogens and the risk of dehydration in young children with acute watery diarrhea: a case-control study. American Journal of Tropical Medicine and Hygiene, 49: 93-100.

19. Rey L (2001). Parasitologia. 3rd edn. Editora Guanabara Koogan AS, Rio de Janeiro, RJ, Brazil.

20. Pass MA, Odedra R \& Batt RM (2000). Multiplex PCRs for identification of Escherichia coli virulence genes. Journal of Clinical Microbiology, 38: 2001-2004.

21. Gunzburg ST, Tornieporth NG \& Riley LW (1995). Identification of enteropathogenic Escherichia coli by PCR-based detection of the bundle forming pilus gene. Journal of Clinical Microbiology, 33: 1375-1377.

22. Franke J, Franke S, Schmidt H et al. (1994). Nucleotide sequence analysis of enteropathogenic Escherichia coli (EPEC) adherence factor probe and development of PCR for rapid detection of EPEC harboring virulence plasmids. Journal of Clinical Microbiology, 32: 2460-2463.

23. Linhares AC, Mascarenhas JD, Gusmão RH et al. (2002). Neonatal rotavirus infection in Belém, northern Brazil: nosocomial transmission of a P [6] G2 strain. Journal of Medical Virology, 67: 418-426.

24. Sperandio V, Kaper JB, Bortolini MR et al. (1998). Characterization of the locus of enterocyte effacement (LEE) in different enteropathogenic Escherichia coli (EPEC) and Shiga-toxin producing Escherichia coli (STEC) serotypes. FEMS Microbiology Letters, 164: 133139.

25. Elias WP, Barros SF, Moreira CG et al. (2002). Enteroaggregative Escherichia coli strains among classical enteropathogenic Escherichia coli O serogroups. Journal of Clinical Microbiology, 40: 35403541.

26. Ghilardi AC, Gomes TAT \& Trabulsi LR (2001). Production of cytolethal distending toxin and other virulence characteristics of Escherichia coli strains of serogroup 086. Memórias do Instituto Oswaldo Cruz, 96: 703-708. 